\title{
Assessing Wind Farm Reliability Using Weather Dependent Failure Rates
}

\author{
G Wilson and D McMillan \\ Wind Energy Systems Centre for Doctoral Training, \\ 204 George Street, University of Strathclyde, Glasgow, G1 1XW \\ E-mail: Graeme.Wilson.100@strath.ac.uk; D.McMillan@strath.ac.uk
}

\begin{abstract}
Using reliability data comprising of two modern, large scale wind farm sites and wind data from two onsite met masts, a model is developed which calculates wind speed dependant failure rates which are used to populate a Markov Chain. Monte Carlo simulation is then exercised to simulate three wind farms which are subjected to controlled wind speed conditions from three separate potential UK sites. The model then calculates and compares wind farm reliability due to corrective maintenance and component failure rates influenced by the wind speed of each of the sites. Results show that the components affected most by changes in average daily wind speed are the control system and the yaw system. A comparison between this model and a more simple estimation of site yield is undertaken. The model takes into account the effects of the wind speed on the cost of operation and maintenance and also includes the impact of longer periods of downtime in the winter months and shorter periods in the summer. By taking these factors into account a more detailed site assessment can be undertaken. There is significant value to this model for operators and manufacturers.
\end{abstract}

\section{Introduction}

A wind turbine's reliability is commonly assessed based on the availability it achieves. The availability is the proportion of time in which an asset is able to produce electricity [1]. The time in which a turbine is unavailable is due to either corrective or preventative maintenance [2][3]. Onshore wind turbines typically perform very well, achieving availabilities between $97 \%-99 \%$ [4].

To increase the availability of a wind turbine more money can be spent on operation and maintenance $(\mathrm{O} \& \mathrm{M})$ with the aim of reducing the probability of a significant downtime occurring. However the cost of O\&M must be weighed up against the cost of lost revenue, which is due to downtime [5]. By increasing the cost of O\&M there is a reduction in downtime, but a point is reached where the direct cost of O\&M is greater than the savings made by increasing the availability of the asset. This is the point when it no longer makes financial sense to increase O\&M spending.

It has been demonstrated that there is a relationship between wind speed and wind turbine failure rates [6]-[8]. Previous research has demonstrated that wind turbine component failure rates can be calculated as a function of wind speed [9][10]. Using this methodology it is possible to model how failures to wind turbine components, and the resultant downtimes, effect energy production and the cost of O\&M.

This paper aims to assess the reliability and productivity of three potential wind farm sites using wind speed dependent failure rates - for which a method has been developed in previous research 
[9][10]. A comparison will then be made between the expected output according to a model that incorporates the wind speed dependent failure rates and one which does not.

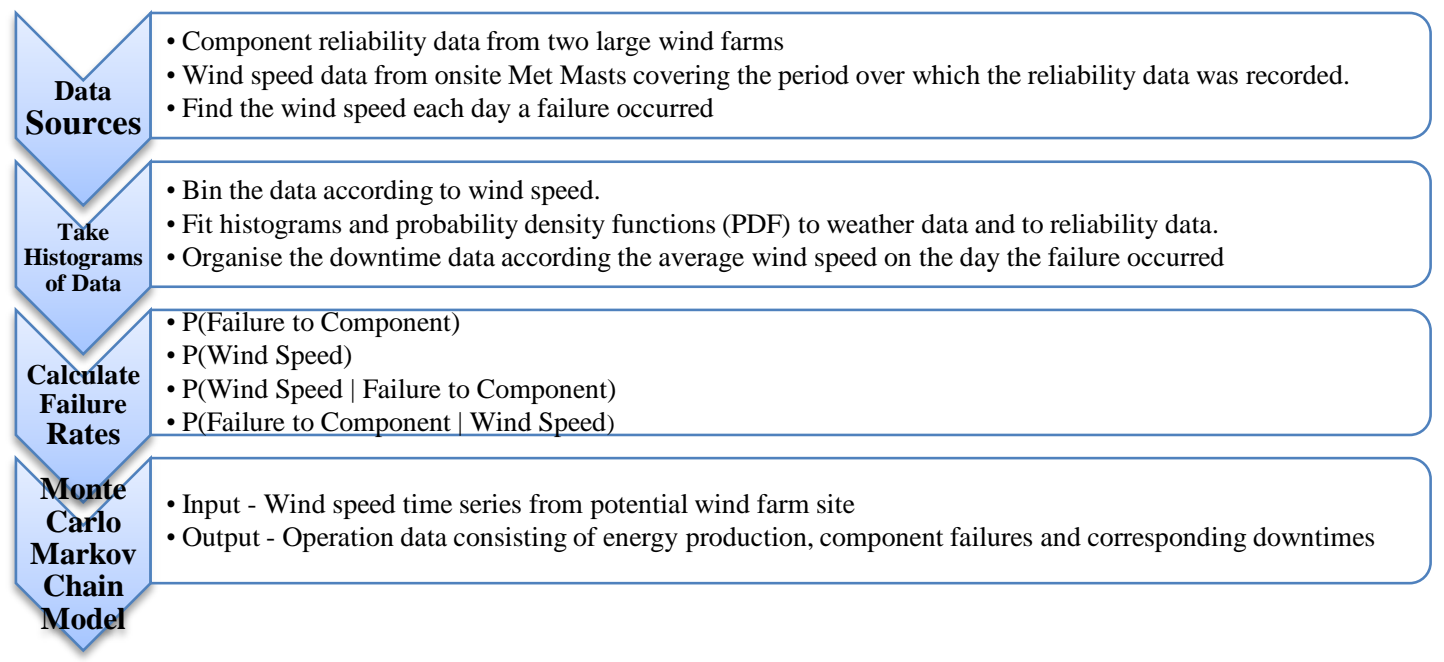

Figure 1: Methodology.

\section{Methodology}

The methodology in this paper is outlined in Figure 1. The datasets come from a reliability record of two onshore wind farms (sites 1 and 2), which comprised of 468 individual failures throughout 381.7 wind turbine years of operation, and meteorological masts which measured the wind speed on each of the sites throughout the same period. The wind turbines on both sites are the same model and are between 3 and 6 years old. They are variable speed, pitch regulated and have a generation capacity of 2.3MW. Only accounting for downtime attributed to corrective maintenance, the average availability of the two sites over the recorded period was $99.44 \%$. Assuming two days of preventative maintenance takes place per wind turbine year this reduces to $98.89 \%$ availability.

Table 1: Component failure rate and data points

\begin{tabular}{lcc}
\hline Components & $\begin{array}{c}\text { Failure Rate (Failures per } \\
\text { wind turbine year) }\end{array}$ & $\begin{array}{c}\text { Failure log entries/data } \\
\text { points }\end{array}$ \\
\hline Emergency Systems & 0.0260 & 2 \\
Met Instruments & 0.0754 & 29 \\
Rotor & 0.0468 & 18 \\
Blade Pitch System & 0.0676 & 26 \\
Drive Train & 0.1561 & 60 \\
Yaw System & 0.1509 & 58 \\
Hydraulic System & 0.0780 & 30 \\
Control System & 0.5203 & 200 \\
Main Generator & 0.0312 & 12 \\
Lifting System & 0.0104 & 4 \\
Nacelle & 0.0156 & 6 \\
Tower & 0.0598 & 23 \\
\hline Total & 1.2381 & 468 \\
\hline
\end{tabular}

The average daily wind speeds of sites 1 and 2 are $5.86 \mathrm{~m} / \mathrm{s}$ and $6.62 \mathrm{~m} / \mathrm{s}$ respectively [10]. Data comes from two onsite met masts - for both Blacklaw and Whitelee - that are assumed to take measurements that are representative of hub height wind speed across the whole of both sites. The wind speed data and reliability data from both sites were combined to produce a dataset which matched each recorded failure with the wind speed that occurred on that site on the day of failure. This 
dataset was then split up into the twelve main components, shown in Table 1 with their respective failure rates calculated using the reliability data. The components which failed the most frequently are the control system, the yaw system and the drive train.

\subsection{Calculating the Failure Rates}

To calculate a component failure rate as a function of wind speed, Bayes Theorem is used; this is shown in equation 1.

$$
P\left(\lambda_{i} \mid w\right)=\frac{P\left(w \mid \lambda_{i}\right) P\left(\lambda_{i}\right)}{P(w)}
$$

If $w$ is the average daily wind speed on a given day, $\lambda_{i}$ represents a failure to component $i$. The term on the left hand side of equation 1 represents the probability of a failure occurring to a component $\left(\lambda_{i}\right)$, given the average daily wind speed $w$. This probability represents the failure rate of component $i$, as a function of average daily wind speed $w$.

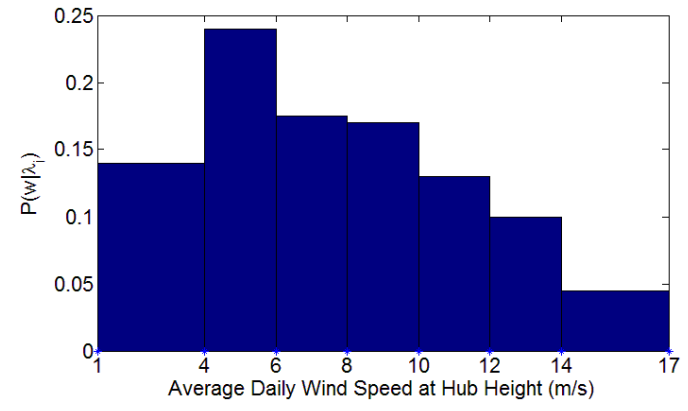

Figure 2. The probability of a wind speed $w$ occurring on a given day, when a failure has occurred to $i$.

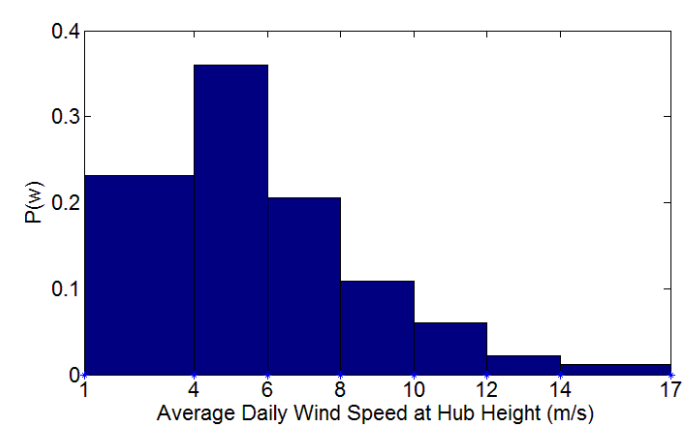

Figure 3. The probability of a wind speed $w$ occurring on a given day.

The terms on the right hand side of equation 1 can be calculated from the reliability data and the met mast data. The term $P\left(w \mid \lambda_{i}\right)$, is the probability of wind speed $w$ occurring, given a failure has occurred to component $i$. This is calculated by taking a normalised histogram (PDF) of the daily average wind speeds recorded on days when a failure occurred to component $i$. The data is binned as shown in Figure 2 and Figure 3. The highest daily average wind speed measured from sites 1 and 2 was $17 \mathrm{~m} / \mathrm{s}$.

$$
\lambda_{i}=\frac{\text { number of failures in given period to component } i}{\text { total operation time (days) }}
$$

The second numerator term is $P\left(\lambda_{i}\right)$, which is the probability of a failure occurring to component $i$ on a given day, otherwise known as the daily failure rate of $i$. This is calculated by using equation 2 . The annual failure rates for each component are shown in Table 1.

The denominator term $P(w)$ represents the probability that the daily average wind speed is $w$. Assuming that daily average wind speeds have the same effect on the failure rates of components on both sites, this is calculated by taking a second PDF, using the same bins as before, of the daily average wind speeds recorded on sites 1 and 2 throughout the period that the reliability data was recorded. The quantity of data from site 1 and 2 differ, so a merged data set was produced which describes the average daily wind speed of both sites proportionally, this is shown in Figure 3. A more 
detailed explanation of this merging can be found in Wilson and McMillan [10]. The average wind speed of this merged dataset is $5.98 \mathrm{~m} / \mathrm{s}$.

Therefore with $P(w), P\left(\lambda_{i}\right)$ and $P\left(w \mid \lambda_{i}\right)$ known, equation 1 was used to calculate the probability of a failure to component $i$, given a daily average wind speed $w, P\left(\lambda_{i} \mid w\right)$. The wind speed dependent failure rates for the control system, yaw system and drive train are shown in Figure 4.

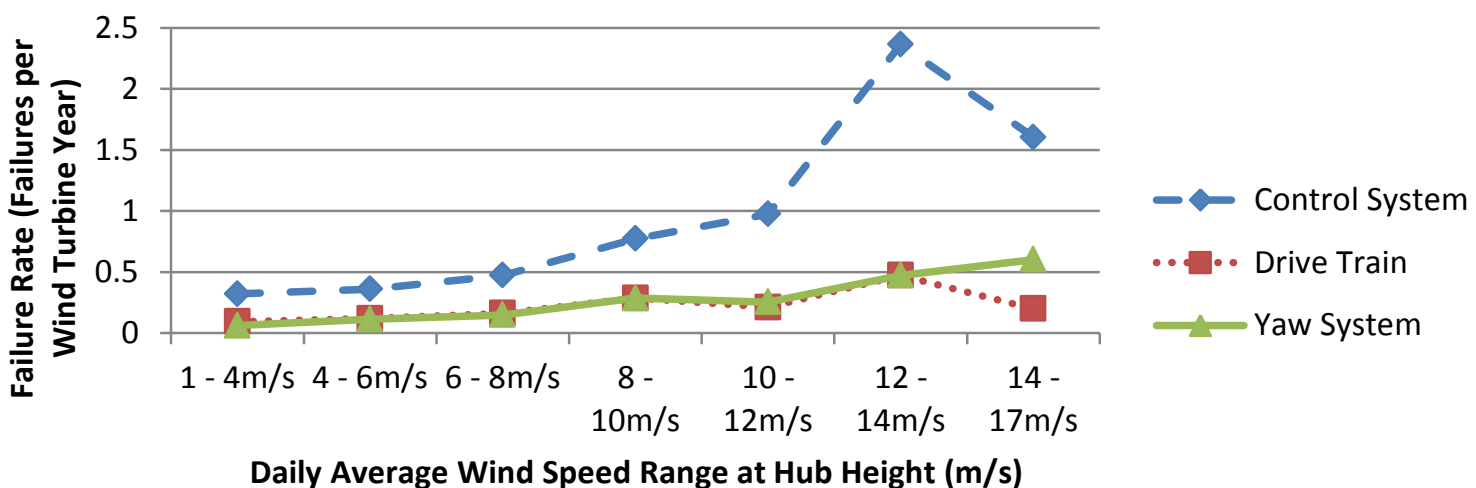

Figure 4: Wind speed dependent failure rates

\subsection{Downtime}

Every failure recorded in the reliability record has a corresponding downtime attributed to it. The downtimes were organised similarly to the recorded failures, first they were split up according to the failed component and then were divided up into the wind speed bins, according to the average daily wind speed when the failure occurred. Figure 5 shows the distribution of downtimes for the control system, yaw system, drive train and the remaining nine components.

Of the failures in the dataset, $83.3 \%$ had a downtime of less than 24 hours; this is an improvement on the downtime distribution calculated by Faulstich et al [11]. This was to be expected as this dataset comprises of a larger and more modern and advanced wind turbine model.

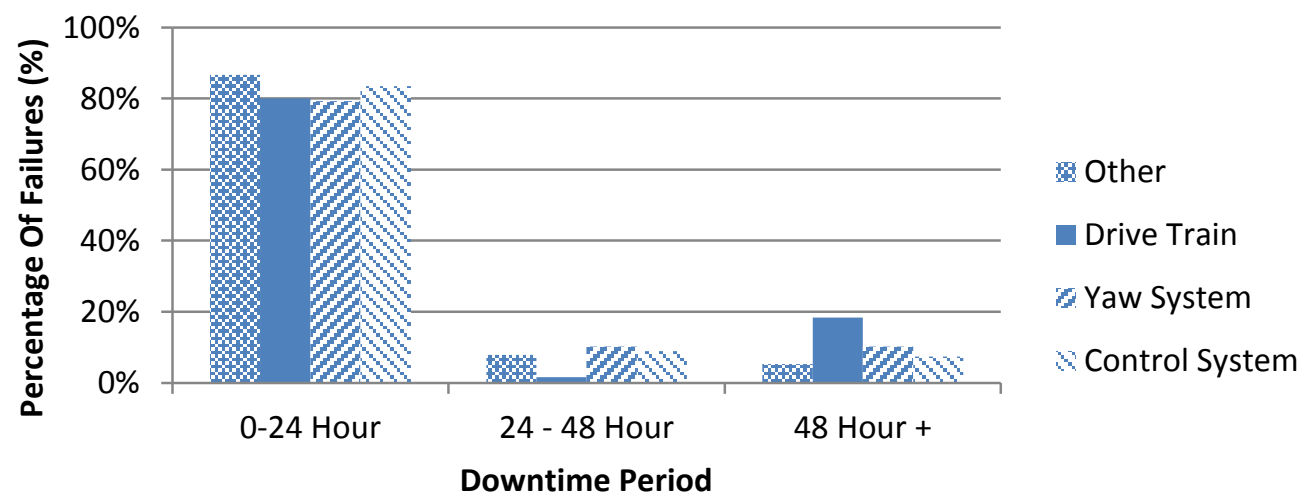

Figure 5: Distribution of downtime

\subsection{Monte Carlo Markov Chain Simulation}

Often the reliability of engineering systems is described as being discrete in that it can exist in one state until a transition occurs and the system changes to another state. These transitions can be represented by a transitional probability matrix. This characteristic means that many systems can be modelled as a Markov process. Markov Chains have been used often to model components and systems [12][13][14][15][16]. 
Each component in this analysis is represented by a markov chain that can exist in one of two states at any time, "operating" or "failed". The transition rate between the "operating" state and the "failed" state is the failure rate $(\lambda)$. If a failure occurs to any component, the whole system stops operating and suffers a downtime before then returning to the "operating" state.

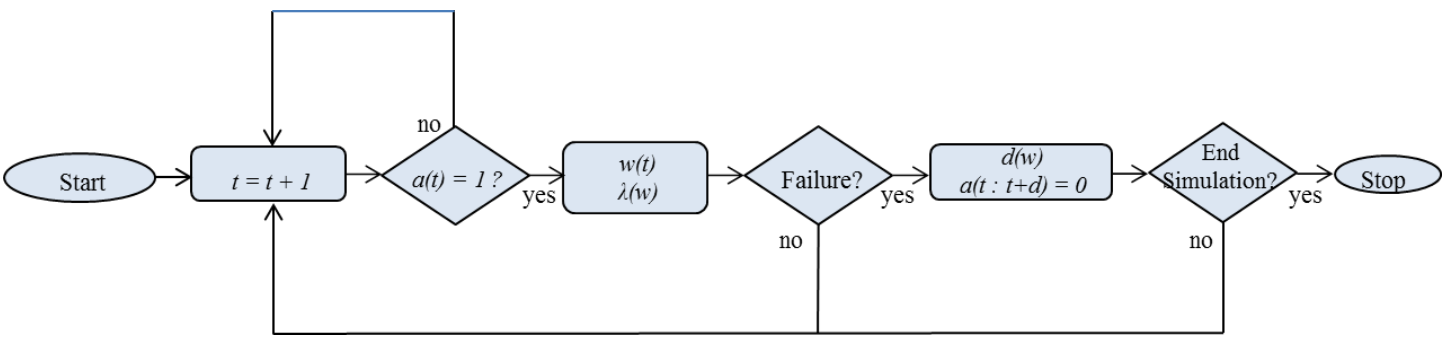

Figure 6: Markov Chain Monte Carlo simulation method.

A Markov Chain Monte Carlo (MCMC) model has been developed which - using the wind speed dependent failure rates calculated in section 2.1, as opposed to the static failure rate in Table 1 determines the impact of wind speeds on the availability of the wind turbine and its components throughout its lifetime. MCMC has been used previously by various authors to model reliability [2][11][14][15]. The lifespan of a wind farm is then simulated using historical wind speed data from a potential wind farm site as a model input. From this simulated operation data, component failure rates, wind farm reliability and energy production can be evaluated.
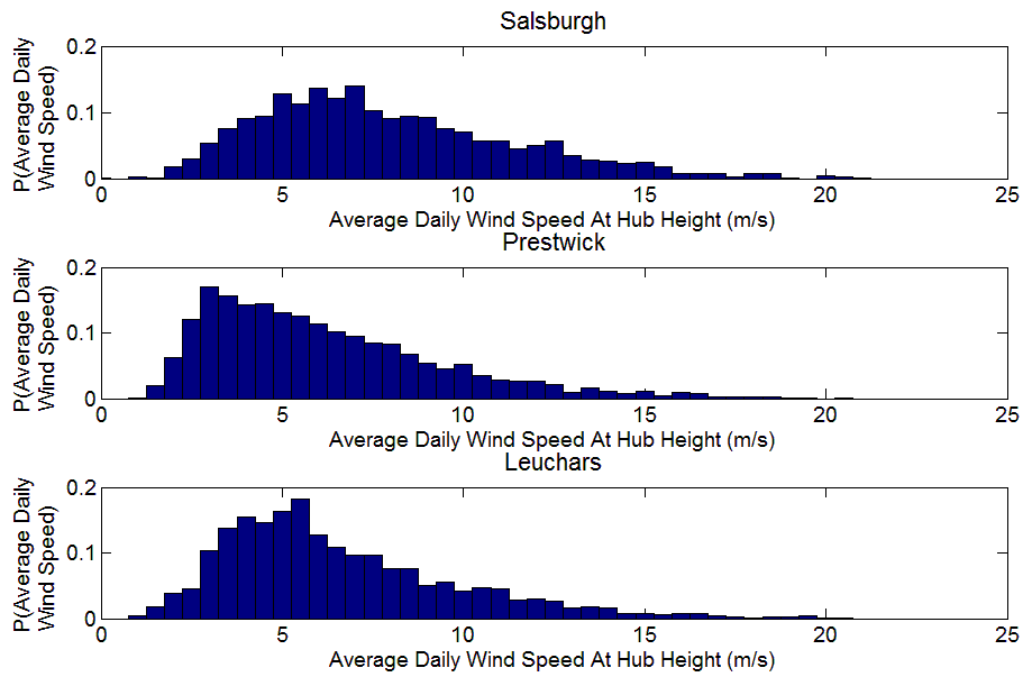

Figure 7: Wind speed distributions for Salsburgh, Prestwick and Leuchars.

In the MCMC simulation, the downtime a component spends in the "failed" state before it returns to the "operating" state is calculated by sampling according to which wind speed bin the average daily speed on the day of failure fits into. If for example the control system fails when the daily wind speed falls between $8 \mathrm{~m} / \mathrm{s}$ and $10 \mathrm{~m} / \mathrm{s}$, there are 34 recorded control system failures which have occurred in the data in that wind speed bin, all with corresponding downtimes. A downtime is selected from this set randomly with uniform probability distribution using Monte Carlo Simulation.

Figure 6 summarises the simulation method where $t$ represents time in days since the start of the simulation, $a$ denotes the availability of the wind turbine, which is either available $(a=1)$ or 
unavailable $(a=0)$ at time $t$. The downtime and failure rate are, respectively, $d$ and $\lambda$. Both $d$ and $\lambda$ are functions of the wind speed, $w$ which is a function of time, $t$. The simulation continues running for 200,000 wind turbine years until the variance of the samples become constant.

\section{Results and Discussion}

The average wind speeds of the potential wind farm sites, Salsburgh, Prestwick and Leuchars are 7.91 $\mathrm{m} / \mathrm{s}, 6.16 \mathrm{~m} / \mathrm{s}$ and $6.59 \mathrm{~m} / \mathrm{s}$ respectively. The data for each site comes from the Met Office [17] and consists of three years of hourly wind speed data - between 2009 and the end of 2011 - recorded using $10 \mathrm{~m}$ masts, which has been aggregated into daily average wind speed. The wind speed profile power law is used to extrapolate the $10 \mathrm{~m}$ wind speeds to a hub height of $82 \mathrm{~m}$, using a surface roughness factor of 0.04 [18]. The wind speed distributions of the sites are shown in Figure 7.

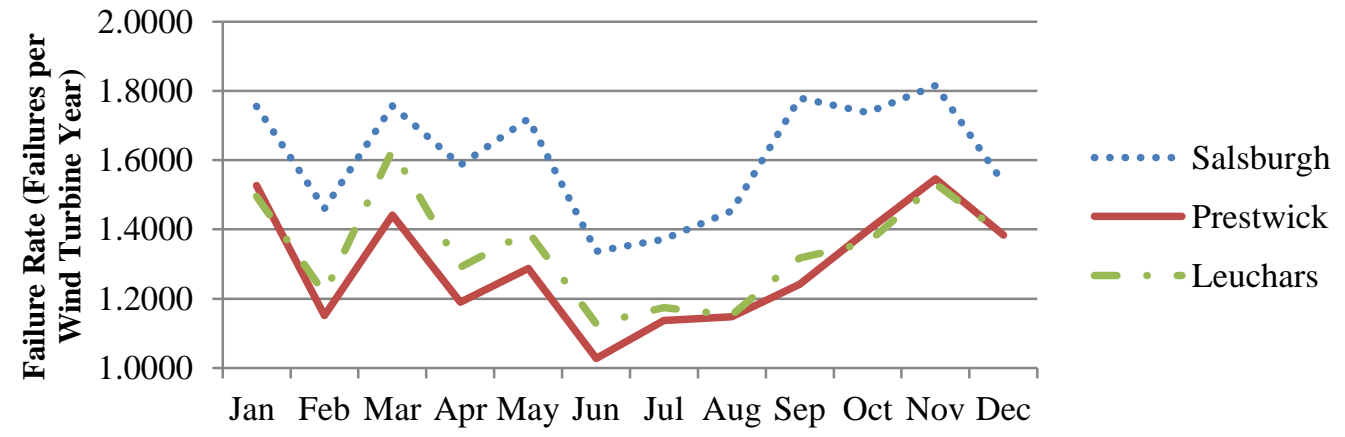

Figure 8: Site seasonal failure rates.

\subsection{Reliability}

Using the model, the failure rate of the three potential wind farms throughout the year is calculated. The mean results from the MCMC simulation is shown in Figure 8. As the three potential sites are all located in Scotland, they followed approximately the same seasonal trend in that the failure rate declined in the summer periods when the wind was calmer and produced higher failure rates in the winter when the wind speed was high. February had lower wind speeds in Scotland than usual during $2009-2011$ which explains the low failure rate for all three sites in February.

Table 2: Calculated site availability and system failure rate

\begin{tabular}{lcc}
\hline Site & $\begin{array}{c}\text { Wind Farm Failure Rate } \\
\text { (Failures per wind turbine year) }\end{array}$ & Availability (\%) \\
\hline Salsburgh & 1.60 & 98.65 \\
Prestwick & 1.29 & 98.84 \\
Leuchars & 1.34 & 98.81 \\
\hline
\end{tabular}

Table 2 shows the annual wind turbine failure rates and availabilities calculated by the model, assuming that the wind turbines on each wind farm are shut down two days a year for preventative maintenance. The site with the highest availability is Prestwick, which also had the lowest average daily wind speed. Equally the site which had the highest wind speed, Salsburgh, has the highest failure rate and lowest availability.

The individual components all react differently to wind speed as shown in Figure 4. The effect of the wind speed on the individual components is shown in Figure 9. The components which are most badly affected by increased wind speeds are the control system and yaw system. The site which differs most to the reliability data is Salsburgh - with the failure rates of the control system and yaw system increasing by $44 \%$ and $45 \%$ respectively. The drive train failure rate increases by $26 \%, 2 \%$ and $6 \%$ on Salsburgh, Prestwick and Leuchars respectively. 


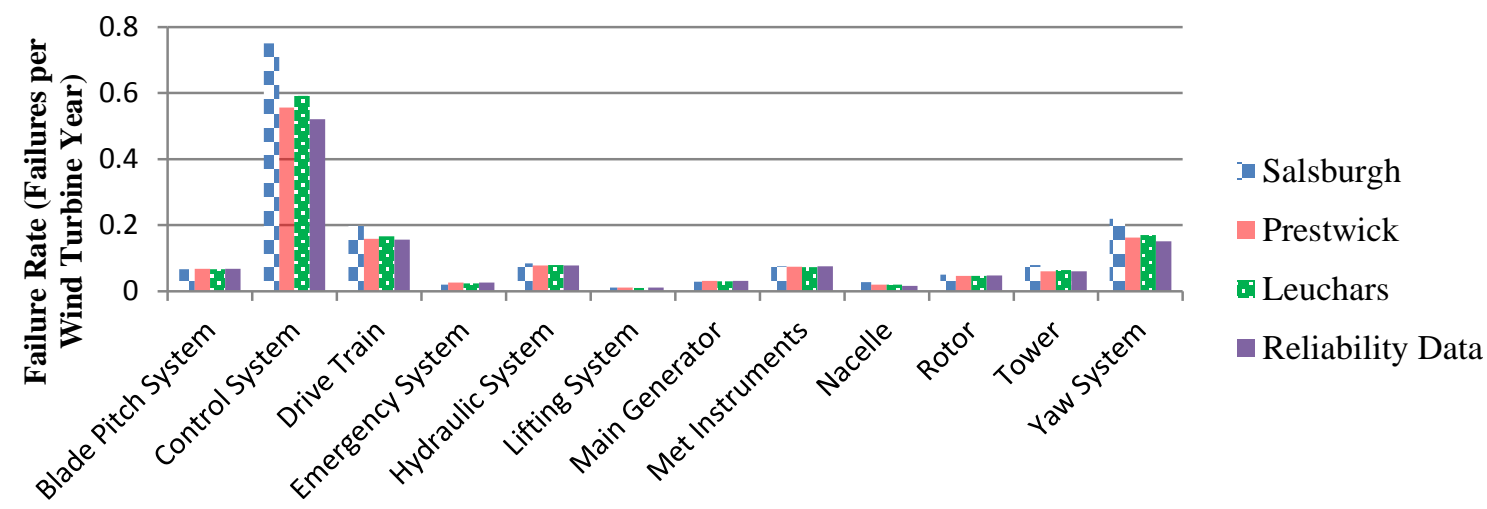

Figure 9: Component failure rates for the three sites calculated by the model compared to the original reliability data.

\subsection{Economic Assessment}

The aim of this section is to assess the economic benefit of using the wind speed dependent failure rate MCMC model as opposed to simply assuming static failure rates and availabilities which are calculated from the reliability data of and are not wind speed dependent.

Table 3: Variables used in calculation of net profit

\begin{tabular}{lcl}
\hline Availability & $\mathrm{a}$ & $98.89 \%$ \\
O\&M Cost per Turbine Year & $\beta$ & $£ 31,242$ \\
Unit Price of Electricity & $\mathrm{s}$ & $80 £ / \mathrm{MWh}$ \\
Capital Expenditure & CapEx & $£ 3,000,000$ \\
Lifetime of Site & 1 & 7300 days \\
\hline
\end{tabular}

Using this static model, the net profit of a site can be calculated using equations 3-5 and the taking the values in Table 3. This static method assumes therefore that each site (using the same model of turbines as site 1 and 2) will be equally reliable and will therefore have the same component failure rates, site availability and O\&M cost, regardless of the wind speed distribution of the site.

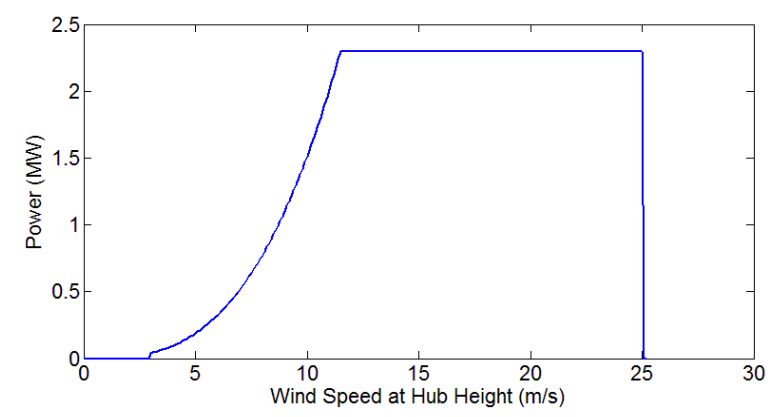

Figure 10: Wind turbine power curve used in calculations.

The availability and O\&M cost in Table 3 have been calculated from the reliability data and are used in equations 3 and 4 . The unit price of electricity in Table 3 is broken down to $£ 40 / \mathrm{MWh}$ as a conservative estimate of the price of a unit of electricity sold on the UK market and the UK subsidy (the Renewable Obligation Certificate) which is also estimated to be roughly $£ 40 / \mathrm{MWh}$ for onshore wind [19][20]. The power curve shown in Figure 10 is used to calculate generated power $P(U(t))$ and is used by both the wind speed dependent MCMC model and the static model. 


$$
\begin{gathered}
\text { Revenue }=a \sum_{t=1}^{l} 24 P(U(t)) s \\
O p E x=\frac{\beta l}{365} \\
\text { Net }=\text { Revenue }- \text { CapEx }- \text { OpEx }
\end{gathered}
$$

Unfortunately replacement part costs and labour costs are not available for the reliability dataset. O\&M costs are typically estimated to be $0.6-0.7 \mathrm{c} € / \mathrm{kWh}$ [21]. Based on the production of sites 1 and 2 this equates to approximately $£ 30,000-£ 35,000$ per wind turbine year.

To calculate approximate costs of O\&M, which take into account wind turbine reliability and not production, downtime is considered as it is known to correlate with failure severity and therefore cost [22]. The downtimes are grouped as $0-24$ hours, $24-48$ hours and over 48 hours; these are assumed to cost $£ 2,500, £ 25,000$ and $£ 250,000$ respectively per failure, not including lost production. Applying these assumed costs to the reliability data results in an O\&M cost of $£ 31,242$ per wind turbine year. This is the cost of O\&M in the static model and compares well with estimates made in Morthorst [21].

The mean results of the MCMC analysis and equation 3 are shown in Table 4 . The percentage difference between the MCMC model mean results and the static model is shown in the difference columns. The revenue of each potential site is estimated simply by using equation 3 . As shown in Table 4 the revenue is over estimated compared to what is calculated by the MCMC model in all three sites. The largest difference is Salsburgh which is calculated by the model to have a reduced availability from the assumed value used in equation 3 . The difference in revenue is also due to the

\begin{tabular}{|c|c|c|c|c|c|c|c|c|c|}
\hline \multirow[b]{2}{*}{ Site } & \multicolumn{3}{|c|}{ Revenue (per turbine) } & \multicolumn{3}{|c|}{ O\&M (per turbine Year) } & \multicolumn{3}{|c|}{ Net (per turbine) } \\
\hline & $\begin{array}{c}\text { MCMC } \\
\text { (£millions) }\end{array}$ & $\begin{array}{c}\text { Static - } \\
\text { Equation } 3 \\
\text { (£millions) }\end{array}$ & $\begin{array}{l}\text { Difference } \\
\text { (MCMC - } \\
\text { Static) }\end{array}$ & $\begin{array}{c}\text { MCMC } \\
(\mathfrak{E})\end{array}$ & $\begin{array}{c}\text { Static - } \\
\beta \\
(\mathfrak{E})\end{array}$ & $\begin{array}{l}\text { Difference } \\
\text { (MCMC - } \\
\text { Static) }\end{array}$ & $\begin{array}{c}\text { MCMC } \\
\text { (fmillions) }\end{array}$ & $\begin{array}{c}\text { Static - } \\
\text { Equation } 5 \\
\text { (fmillions) }\end{array}$ & $\begin{array}{c}\text { Difference } \\
\text { (MCMC - } \\
\text { Static) }\end{array}$ \\
\hline Salsburgh & 12.43 & 12.52 & $-0.72 \%$ & 49313 & 31242 & $57.84 \%$ & 8.44 & 8.90 & $-5.07 \%$ \\
\hline Prestwick & 7.66 & 7.67 & $-0.13 \%$ & 34787 & 31242 & $11.35 \%$ & 3.96 & 4.05 & $-2.00 \%$ \\
\hline Leuchars & 8.58 & 8.59 & $-0.12 \%$ & 36742 & 31242 & $17.60 \%$ & 4.85 & 4.97 & $-2.42 \%$ \\
\hline
\end{tabular}
wind turbine failing, according to the model, at times of the year when the wind is at its strongest.

Table 4: Comparison between model and equation 5

The O\&M cost estimated by the MCMC model is greater for each site than that calculated for the static model. The proportion of failures in the Salsburgh simulation which lead to downtimes of greater than 48 hours is $11.81 \%$, compared to $8.55 \%$ of failures in the reliability data. This redistribution in severity of failures, along with a higher overall failure rate, accounts for the $57.84 \%$ increase in projected O\&M cost per wind turbine year. The static model does not account for this in its calculation.

The net income of each potential site is estimated using equation 5 and the operational output of the MCMC model. Comparing the results of the two methods, the difference between them shows that by neglecting the effect of wind speed dependent failure rates, the net income of the three sites are over estimated. Salsburgh is the site with the highest difference between the model and the non-model estimates, this is because of its greater average wind speed which increases the cost of O\&M. However Prestwick - which has a relatively low wind speed - still shows a difference of $2.00 \%$ in net income when comparing the methods. For a moderately sized wind farm of 50 wind turbines, this 2.00 $\%$ difference would equate to $£ 4.5$ million in lost revenue over twenty years.

There is a small difference in revenue shown in Table 4 for the three sites, calculated using both methods. This is due to the effects of the seasonal wind speeds on wind turbine reliability and productivity. Figure 11 shows the average power generated per month and the percentage of power 
lost on average each month because of component failures and resultant downtimes from the mean results of the MCMC simulation. As shown in Figure 11 the percentage of power lost to potential power increases in the winter months and decreases in the summer months. This seasonal trend cannot be modelled using equations 3- 5. The MCMC model takes account of this and any change in availability and the result is a difference of $0.72 \%, 0.13 \%$ and $0.12 \%$ in revenue for Salsburgh, Prestwick and Leuchars respectively.

If a developer decided to build a wind farm at Salsburgh and chose take out a warranty with the original equipment manufacturer (OEM), they would benefit if the OEM did not account for the wind speed dependent failure rates. However this may mean that the OEM would recoup their costs at Salsburgh by increasing the price of the warranty on other sites. For a developer at a site with a less productive resource which causes fewer failures, such as Prestwick or Leuchars, this resultant higher O\&M cost would make the investment less economical. However if the OEM factored the effects of individual site wind speed into their warranty, the costs to the operator would better reflect the reliability and the risk of their site.

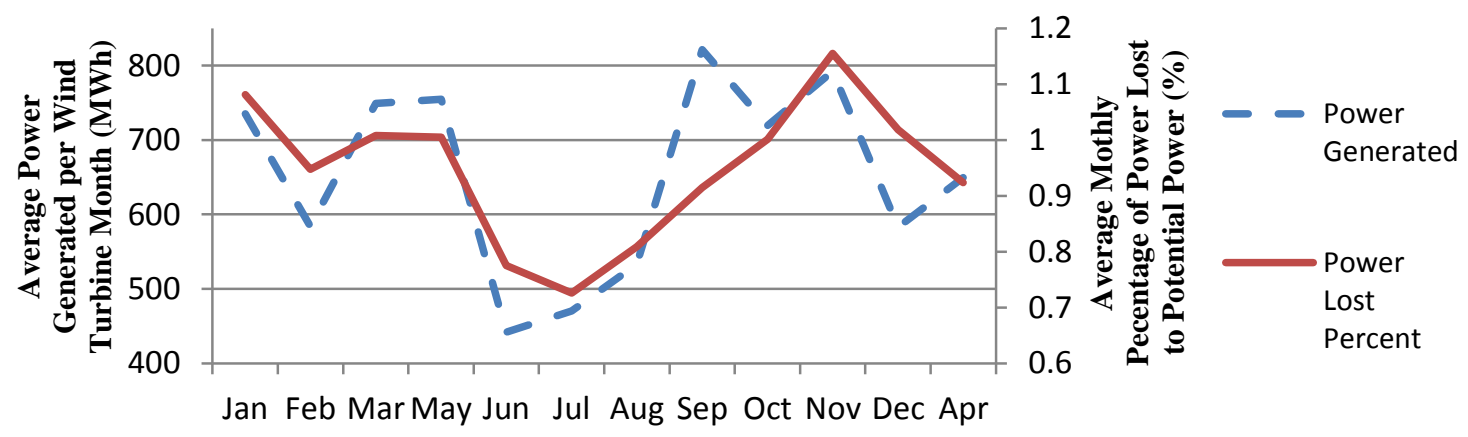

Figure 11: Salsburgh average monthly power generated and percentage of potential power lost due to failures.

Banks and other organisations that cover the operator's initial investment would also benefit from factoring in the impact of wind speed on reliability. For sites with high wind speeds, such as Salsburgh, there are significant differences between net incomes calculated when accounting for the impact of wind speed on reliability and when using static failure rates. According to Table 4, a wind farm sited at Salsburgh would generate $5.07 \%$ less income than expected according to equation 5 .

This is of course assuming a static O\&M cost. In reality the cost of O\&M would rise as the wind turbine and its components follow a bath-tub curve and become less reliable and more expensive to maintain [22]. More work must be undertaken to understand how the wind speed effects wind turbines of different ages. As described in section 2, the wind turbines in this analysis are between 3 and 6 years old. The reliability data therefore shows a period of time during which the wind turbines would be expected to be very reliable and be operating at the bottom of the bath-tub curve [22].

\section{Conclusion}

This paper has demonstrated a method for assessing the reliability of a potential wind farm site by applying wind speed dependent failure rates calculated from a multi megawatt wind turbine reliability dataset and onsite met mast data. The advantages of using this method, as opposed to using static component failure rates, is that more informative O\&M costs can be calculated and the effect of seasonal changes on wind turbine operation can be accounted for.

The site which will produce the most electricity is Salsburgh, which also has the strongest wind resource and the highest predicted failure rate. The model estimated an O\&M cost which was $57.84 \%$ higher than expected. The effect of more frequent and longer downtimes in the winter also reduced the estimated revenue by $0.72 \%$. The effect on the net income was a reduction of $£ 460,000$ the lifespan of the wind farm. 
Future research will assess the impact of the wind speed on the reliability of wind turbines of different ages. Currently the results only describes the impact of the wind speed on one model of wind turbine - to make the model more useful, data from other wind turbine models will need to be used to calibrate the model. From this site specific model, more detailed assessments could be made including spares optimisation based on seasonal reliability.

To properly assess the reliability and economic viability of a site, it is therefore important that the impact of the wind speed on the reliability of the components is assessed. The research in this paper will be of particular interest to operators and wind turbine manufacturers.

\section{Acknowledgements}

The authors would like to thank the EPSRC for funding this research. Grant number EP/G037728/1.

\section{References}

[1] P. J. Tavner, H. Long, and Y. Feng, "Early experiences with UK round 1 offshore wind farms," Proc. ICE - Energy, vol. 163, no. 4, pp. 167-181, Nov. 2010.

[2] F. Besnard, K. Fischer, and L. Bertling, "Reliability-Centred Asset Maintenance - A step towards enhanced reliability , availability, and profitability of wind power plants," in EEE PES Conference on Innovative Smart Grid Technologies Europe, 2010, pp. 1-8.

[3] L. Bertling, R. Eriksson, and R. N. Allan, "Relation between preventive maintenance and reliability," in IEEE Porto Power Tech Conference, 2001, vol 4.

[4] G. J. W. Van Bussel and a R. Henderson, "State of the Art and Technology Trends for Offshore Wind Energy: Operation and Maintenance Issues," Offshore Conroe TX, pp. 10-12, 2001.

[5] J. Phillips, P. Reynolds, L. Gosden, G. Hemmingsen, I. Mcdonald, G. Mackay, W. Hines, P. O. Repower, J. Brown, and J. Beresford, "A Guide to UK Offshore Wind Operations and Maintenance." Scottish enterpirse and the Crown Estate.

[6] M. Wilkinson, G. L. G. Hassan, S. Vincent, S. Lane, B. Bs, T. Van Delft, and K. Harman, "The Effect of Environmental Parameters on Wind Turbine Reliability," in EWEA 2012 Copenhagen, Denmark, 2012.

[7] B. Hahn, “" Zeitlicher Zusammenhang von Schadenshäufigkeit und Windgeschwindigkeit ,"” in FGW-Workshop Einflub der Witterung auf Windenergieanlagen, 1997.

[8] P. J. Tavner, D. M. Greenwood, M. W. G. Whittle, R. Gindele, S. Faulstich, and B. Hahn, "Study of weather and location effects on wind turbine," Wind Energy, vol 16 no. 2, pp. 175-187, 2013.

[9] G. Wilson and D. McMillan, "Modelling the Impact of the Environment on Offshore Wind Turbine Failure Rates," in EWEA Offshore, Frankfurt, Germany, 2013.

[10] G. Wilson and D. McMillan, "Quantifying the Impact of Wind Speed on Wind Turbine Component Failure Rates," in EWEA 2014, Barcelona, Spain, 2014.

[11] S. Faulstich, B. Hahn, P. Lyding, and P. Tavner, "Reliability of offshore turbines - identifying risks by onshore experience." EWEA Offshore, Stockholm, Sweden. 2009.

[12] F. Castro Sayas and R. N. Allan, "Generation availability assessment of wind farms," IEE Proc. Gener. Transm. Distrib., vol. 143, no. 5, p. 507, 1996.

[13] D. McMillan and G. W. Ault, "Quantification of Condition Monitoring Benefit for offshore wind turbines," Wind Eng., vol. 31, no. 4, 2007.

[14] F. Besnard and L. Bertling, “An Approach for Condition-Based Maintenance Optimization Applied to Wind Turbine Blades," IEEE Trans. Sustain. Energy, vol. 1, no. 2, pp. 77-83, 2010.

[15] R. Billington and R. N. Allan, Reliability Evaluation of engineering Systems: Concepts and Techniques, 1 st ed. New York: Plenum Press, 1983.

[16] D. McMillan and G. W. Ault, "Techno-economic comparison of operational aspects for direct drive and gearboxdriven wind turbines," IEEE Trans. Energy Convers., vol. 25, no. 1, pp. 191-198, 2010.

[17] Met Office, "Met Office Integrated Data Archive System Land and Marine Surface Stations Data," 14-Oct-2013. [Online]. Available: http://badc.nerc.ac.uk/view/badc.nerc.ac.uk_ATOM_dataent_ukmo-midas.

[18] T. Burton, D. Sharpe, N. Jenkins, and E. Bossanyi, Wind Energy Handbook, 1st ed. Chichester: John Wiley and Sons Inc, 2008, p. 19.

[19] Mott MacDonald, "UK Electricity Generation Costs Update," 2010.

[20] Ofgem, "Renewables Obligation: Guidance for Generators," London, 2013.

[21] P. E. Morthorst and S. Awerbuch, "The Economics of Wind Energy," EWEA. 2009.

[22] S. Faulstich, B. Hahn, and P. J. Tavner, "Wind turbine downtime and its importance for offshore deployment," Wind Energy, vol. 14, no. 3, pp. 327-337, 2011. 